\title{
Highlights of the International Conference on Catalytic Gold, Cape Town, South Africa, 2-5 April 2001
}

\author{
David T Thompson \\ 'Newlands', The Village, Whitchurch Hill, Reading, RG8 7PN, UK \\ E-mail:DTThompson@aol.com
}

\begin{abstract}
The recent discoveries in a number of different laboratories that gold can be prepared in catalytically-active forms, and that these catalysts have special and attractive properties with commercial potential $(1-5)$ were highlighted during this three day conference. This meeting brought together for the first time the world's leading researchers in this field, and industrialists were able to assess the usefulness of the results obtained to date. Eighty-five delegates from fifteen different countries attended this conference, which was sponsored by both mining and industrial companies, eg World Gold Council, Anglogold, Mintek, and Engelhard-CLAL. There were representatives from six commercial applications companies and others were represented indirectly. There was the feeling of excitement often associated with the discovery of new science, particularly when there is also promise of new applications which will benefit society.
\end{abstract}

The opening address was given by the South African Minister of Arts, Culture, Science and Technology, Dr S Ngubane. He said that it was highly appropriate that a conference on gold should take place in Southern Africa, source to date of at least 47,000 tons, or almost exactly one third of all the world's gold, and it has been estimated that another 36,000 tons of gold remain, although some of it is not recoverable at present gold prices. Gold has been mined and used by the inhabitants of Southern Africa for at least 2,000 years: a beautiful gold rhinoceros is one of the many interesting artefacts recovered from the ancient city of Mapungubwe, in the far north of South Africa.

There is enough gold in the world to support many future industrial applications and this is therefore good news for South Africa because gold and the gold mining industry contributes in a significant way to its economy. Consequently the South African government is pleased to note that the interest in using gold as a catalyst is growing.
In my chairman's introduction for the first session I commented on how my work as Technical Editor for Gold Bulletin has given me a good feel for uses of gold, which are not really very many: not as wide a spread as for the platinum group metals. One of the reasons for this is comparative lack of investigation: we are taught, from our earliest school chemistry lessons of the incorruptibility and lack of corrosivity of gold. Fortunately there were people present in the Cape Town audience who had disregarded this generalization and have found that catalysis by gold has special characteristics both when used homogeneously in solution and when used heterogeneously in the gas or liquid phase. I had learnt about new gold chemistry and new gold catalysis over the past five years or so, largely from my editor's chair, and one of the exciting prospects for this conference was the opportunity of meeting many of these pioneer practitioners!

The conference was divided into four sessions, ie 'Catalytic Gold in the Synthesis of Fine Chemicals', 'Physical Characterization of Small Gold Particles', 'Catalytic Gold in Industrial Processes' and 'Catalytic Gold in Environmental Control'. There were five keynote lectures, and an evening workshop where lively discussion took place. The conference activities are summarized below:

\section{KEYNOTE LECTURES}

Gold - A Relatively New Catalyst, Geoffrey C Bond, Rickmansworth, UK

Gold Chemistry and Gold Catalysts, Hubert Schmidbaur, Technical University of Munich, Germany 


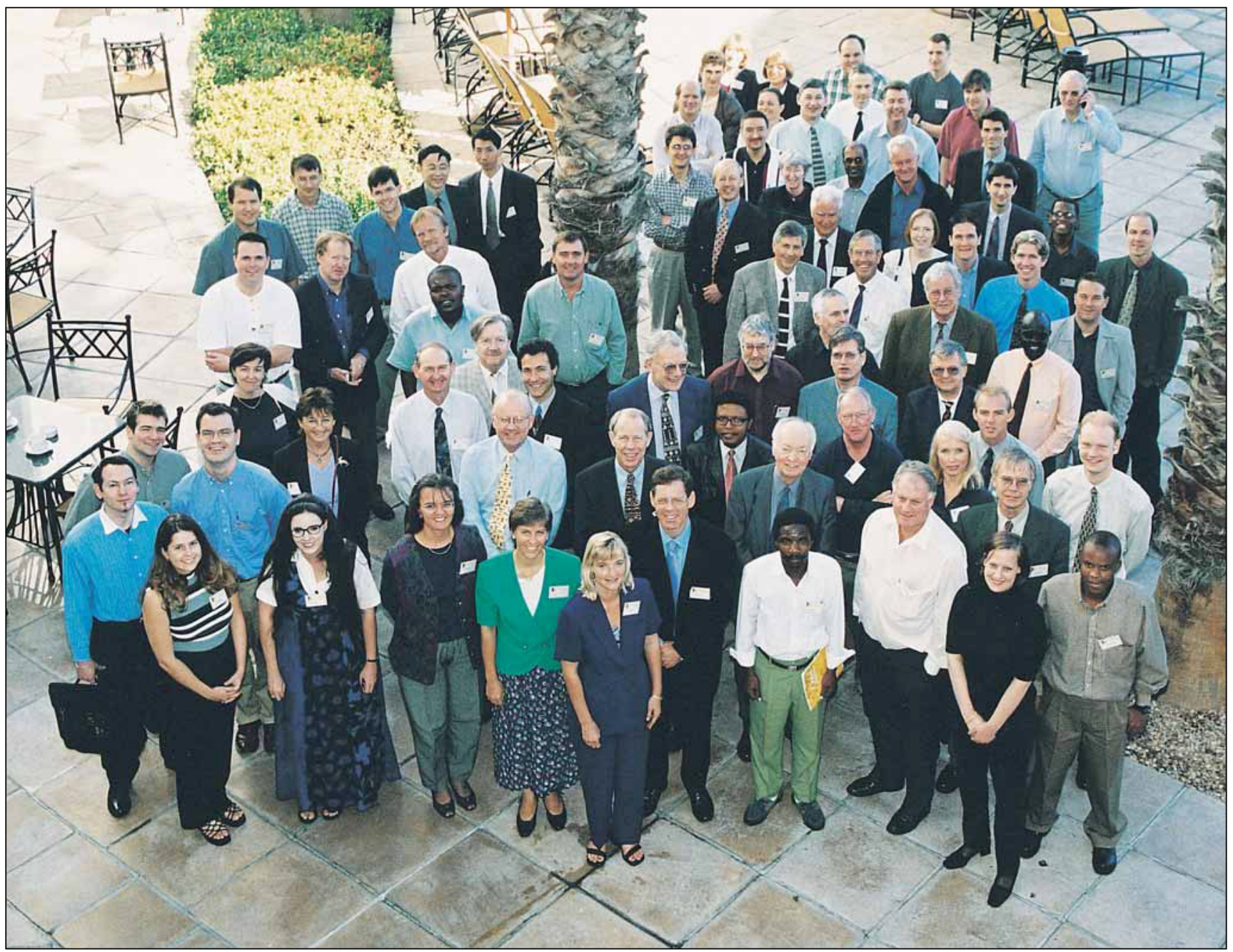

Participants at the Catalytic Gold Conference, Cape Town, 2-5 April 2001

Gold Catalysts in Chemical Processing, Graham J Hutchings, Cardiff University, UK

Supported Gold Catalysts for CO Oxidation and Other Environmentally Important Reactions, Masatake Haruta, Director, Research Institute for Green Technology, Tsukuba, Japan

The Catalyst Design Challenges Posed by New Fuel-Cell Technologies, Stan Golunski, Johnson Matthey Technology Centre, Reading, UK

The first talk was presented by Professor Geoffrey Bond (Rickmansworth, UK) who had studied some aspects of gold catalysis as early as the 1970s. Work performed with gold catalysts before about 1980 was briefly summarized. In fact, the first paper on gold catalysis was published in 1906 (4). The early indications of the importance of using very small gold particles were indicated. The apparent contrast between silver and gold in catalysing carbon monoxide oxidation was anticipated by studies in matrix isolation chemistry. The unexpected and in some ways unique properties of gold are attributable to the operation of a relativistic effect which stabilizes the $6 s^{2}$ electron pair. Essential requirements for high oxidation activity include: small particle size, use of a reactive support, and a preparative method which produces the desired size of particle in intimate contact with the support. Surface atoms on such small particles behave more like individual atoms, and this, together with the relativistic factor may help to explain why gold can be such an effective catalyst. Gold catalysis is a very special phenomenon, only manifesting itself under quite specific circumstances: realising this, it is not surprising that its arrival was delayed for so long. In this sense gold is a relatively new catalyst. 
The second keynote lecture was given by Professor Hubert Schmidbaur. Gold forms chemical compounds with a large variety of oxidation states $(-1$ to +5$)$ and coordination numbers ( 2 to $7 ; 12$ in the metal). The oxidation potential of the metal is determined to a large extent by relativistic effects, as are the atomic and ionic radii, making gold the most electronegative metal in the Periodic Table with an unexpectedly small atomic radius. The low-coordination numbers (linear two- or square-planar four-coordination) mean free access to the metal not only for nucleophilic and electrophilic substrates, but also for mutual interactions between gold atoms. However, although entrance to coordination sites at the metal atom for molecules is generally not impaired sterically, the activation of the substrates is not always sufficient for stoichiometric or catalytic reactions. Examples of reversible oxidative addition and reductive elimination are still small in number. The gold atoms at surfaces of bulk gold metal and of small size gold particles act very much like gold atoms in low-valent gold compounds. These parallels were discussed with respect to their relevance to homogeneous and heterogeneous catalysis.

Professor Graham Hutchings gave a talk which consisted of two parts: his pioneer work on the use of gold choride catalysts for hydrochlorination, and the much more recent investigations into selective hydrogenation using gold on supported transition metal oxides such as zinc oxide and zirconia. The very high standard electrode potential of gold $(+1.4 \mathrm{~V})$ lead him to forecast that gold would be the most effective catalyst for hydrochlorination of ethyne. In the 1980s, it was clearly demonstrated that a gold on carbon catalyst was best for the production of vinyl chloride using this route: this was in fact the first time that a gold catalyst had been shown to have the highest activity in any catalytic reaction. Co-feeding nitric oxide with the reactants was shown to be effective in preventing the deactivation of the catalyst. Full details of this work are given in an earlier Gold Bulletin article (1). Around a ton of gold would have been required for each commercial plant, but this was regarded as too much in the 1980s, when the price of gold was high (around three times its present level) and the demand situation for gold was different from today.

The selective hydrogenation of $\alpha, \beta$-unsaturated aldehydes to the corresponding unsaturated alcohol poses a very difficult challenge. In recent work, supported gold catalysts have been shown to give high selectivities, for example in the hydrogenation of crotonaldehyde. It is interesting that pretreatment of the $\mathrm{Au} / \mathrm{ZnO}$ and $\mathrm{Au} / \mathrm{ZrO}_{2}$ catalysts with thiophene can considerably promote the catalytic performance, and the promotional effect and the selectivity to the unsaturated alcohols was found to be dependent on the nature of the support and the gold particle size. High selectivity can be associated with relatively large gold particles $(\geq 10 \mathrm{~nm})$.

Dr Masatake Haruta described use of supported gold catalysts for carbon monoxide oxidation and other environmentally important reactions. Gold becomes catalytically very active when three requirements are fulfilled: ie strong contact with the support around the perimeter of the gold particles, an appropriate selection of metal oxide support, and control of particle size (to below ca $5 \mathrm{~nm}$ ). The supported gold catalysts are active for carbon monoxide oxidation even at a temperature as low as 90 $\mathrm{K}$ and even in the presence of moisture. There are two major routes for carbon monoxide oxidation over supported gold catalysts: the reaction over the gold surfaces and the reaction over the perimeter interface. The former reaction takes place with a very low apparent activation energy. Therefore the rate does not decrease even at low temperatures without accumulation of carbonate species. The second reaction proceeds at a rate higher by about ten times than that of the former at temperatures above $300 \mathrm{~K}$, and the accumulation of carbonate species at the perimeter interface between 200 and $300 \mathrm{~K}$ is a significant factor. Consequently, the apparent activation energies for the reaction at the perimeter interface are $20-40 \mathrm{~kJ} / \mathrm{mole}$ and almost zero $\mathrm{kJ} / \mathrm{mole}$ at temperatures below and above $300 \mathrm{~K}$, respectively. FTIR and kinetic studies on supported gold catalysts indicate that $\mathrm{CO}$ is adsorbed on step and perimeter sites over the gold surfaces and molecular oxygen is non-dissociatively adsorbed at the perimeter interface. $\mathrm{CO}$ adsorbed on the gold surfaces most likely reacts with $\mathrm{O}_{2}^{-}$to form $\mathrm{CO}_{2}$ in the gas phase and $\mathrm{O}-\mathrm{Au}=\mathrm{CO}$ adsorbed species. The latter is readily decomposed to form $\mathrm{CO}_{2}$ and bare gold surfaces. The degree to which carbonate species are accumulated on the support surfaces depends on reaction temperature: most of these behave as spectators but those accumulated near the perimeter interface deactivate the catalyst.

Gold catalyst is already used commercially in Japan for the removal of odours from toilets. Other odour abatement applications are foreseen as is the possible use of gold catalysts to remove nitrogen oxides from diesel exhausts and to decompose dioxins in incinerators. Gold also has potential for use in fuel cell systems and gas sensors. 
The challenges posed by new fuel-cell technologies was discussed by Dr Stan Golunski of Johnson Matthey. This talk was included in the programme in order to assess whether there is likely to be an upsurge of interest in gold catalysts for application in other fuel cell systems. This could include use for the low temperature shift and other purification aspects required for the gas feed streams.

A fuel cell can be classified according to its operating temperature, which in turn often defines its suitability for particular applications. Solid polymer, alkaline and phosphoric acid fuel cells operate at low temperatures $\left(200^{\circ} \mathrm{C}\right)$, while molten carbonate and solid oxide fuel cells require temperatures in excess of $600^{\circ} \mathrm{C}$. The relatively poor thermal stability of dispersed gold means that it is naturally suited to the low temperature category, as demonstrated by its existing commercial use in the Pt-Au cathodes of alkaline fuel cells. Other opportunities for the use of gold in low temperature fuel cell systems could emerge as the level of interest in their use continues to grow.

The emergent markets for mobile and domestic clean power-generation particularly favour the solid polymer fuel cell (SPFC), with its high power density and ease of start up. The absence of a hydrogen economy, though, means that in the short to medium term most mobile and domestic SPFC stacks will need to be coupled with a fuel processor. This creates new issues, but also provides new catalytic opportunities.

The reformate produced by a fuel processor has to be purified before the gas reaches the SPFC anodes, and the energy contained in any hydrogen that is unconverted within the stack needs to be recycled. Overall, an SPFC power-generation system may contain more than five different types of catalyst. In principle, gold could be a major component of any one, or all, of these. However, its use will depend on it enabling SPFC systems to meet critical design targets for start up, efficiency, lifetime, size, weight and cost. Gold catalysts will need to have measurable advantages over the other precious metal, base metal and metal oxide catalysts currently being evaluated.

\section{CONFERENCE PAPERS}

The titles of the papers in each section are listed below, together with their authors, followed by a brief account of their highlights. Most of the papers will be published in full in a special issue of Catalysis Today for which I am Guest Editor. There is consequently no attempt to make this review comprehensive.

\section{Catalytic Gold in the Synthesis of Fine Chemicals}

Application of Gold Catalysts to Selective Liquid Phase Oxidation, L Prati and M Rossi, University of Milan, Italy

Highly Selective Gold-Catalysed Synthesis of Arenes, A S K Hashmi, University of Frankfurt, Germany

\section{Gold(I) Catalysts for the Addition of Alcohols to Alkynes:} an Industrial Perspective, J H Teles, BASF, Ludwigshafen, Germany

Stoichiometric and Catalytic Reactions of Gold Compounds Utilizing Ionic Liquids, M Deetlefs and H G Raubenheimer, University of Stellenbosch, South Africa

Michele Rossi described applications of gold catalysis to selective liquid phase oxidation reactions of diols, polyols, aldehydes and hydroxyaldehydes under mild conditions. The microporous nature of carbon supports provides a shield for small gold particles and a limit for their mean diameter. The activation of an alcoholic group requires the presence of a base, whereas aldehydes are smoothly oxidized to carboxylic acid. Compared with platinum or palladium, appropriate gold catalysts show better resistance to deactivation, providing a convenient method for use in industry on several types of feedstock. Aminoalcohols can also be selectively oxidized to aminoacid in slightly alkaline solution: in this application gold is remarkably superior to other catalysts because historically the free amino group represents a drawback for catalytic oxidation owing to its strong interaction with most catalytic metals, leading to their deactivation.

Stephen Hashmi gave a talk on the highly selective gold-catalysed synthesis of arenes. He described a new homogeneous gold-catalysed reaction for the formation of tetra- up to hexa-substituted arenes from readily available precursors. The reaction proceeds at room temperature under neutral conditions, no precautions such as exclusion of water or oxygen being necessary. $\mathrm{He}$ also investigated a range of other transition metals, Brønsted and Lewis acids, under high temperature and high pressure conditions, but only gold possessed the unique ability to catalyse the arene formation.

Henrique Teles (BASF) described a new class of catalysts for the addition of alcohols to alkynes. The active species is a cationic gold(I) complex of the form $\mathrm{L}-\mathrm{Au}^{+}$(where $\mathrm{L}$ is usually triphenylphosphine) which can be generated in situ by reacting $\mathrm{L}-\mathrm{Au}-\mathrm{CH}_{3}$ with methanesulfonic or sulfuric acid. This catalyst proved 
to be extremely efficient. The total turnover numbers can be as high as $2 \times 10^{5}$ with turnover frequencies up to 1.5 $\mathrm{s}^{-1}$ (at $40^{\circ} \mathrm{C}$ ). The mechanism of catalysis has been studied by changing the catalyst structure and reaction conditions. The experimental results were supported by high level ab initio modelling of the reaction mechanism. Both experiment and theory agree in that the mechanism involves an activation of the alkyne by a cationic gold(I)complex. Using these gold(I)-catalysts and readily available alkynes efficient routes to new and established intermediates were developed. Not only alcohols but in special cases even carboxylic acids can be added to alkynes in good yields and with high reaction rates.

Professor Raubenheimer talked about use of ionic liquids as alternative media for both stoichiometric and catalytic reactions. The first low melting $\left(80^{\circ} \mathrm{C}\right)$ thiazolium compound with tetrachloroaurate $\left(\mathrm{AuCl}^{4-}\right)$ as counter ion has recently been characterized. Attempts to deprotonate such compounds with a strong base to give carbene complexes, led to non-isolable compounds. However, the stoichiometric transformation of an ionic liquid to gold(I) carbene complexes has been achieved.

Acetylenes are hydrated by wet methanol to ketones in the presence of catalytic amounts of sodium tetrachloroaurate $\left(\mathrm{NaAuCl}_{4}\right)$ and to acetals in the absence of moisture. These catalytic reactions also occurred in the ionic liquids $[\mathrm{BMIM}]^{+}\left[\mathrm{BF}_{4}\right]^{-}$and $[\mathrm{BMIM}]^{+}\left[\mathrm{PF}_{6}\right]^{-}$, albeit with different products as well as yields. A chloroalkene was also produced together with ketones.

\section{Physical Characterization of Small Gold Particles}

Adsorption and Reaction on Gold-Titania Model Systems, $\mathrm{N}$ Nilius, $\mathrm{N}$ Ernst and H-J Freund, Fritz-Haber Institute, Berlin

Study of Active Sites of Gold Catalysts for the Processes of Selective and Deep Oxidation, A N Pestryakov, V V Lunin, D I Kochubey and N Bogdanchikova, Tomsk and Moscow State Universities and Materials Science Centre, Ensenada, Mexico

Supported Gold Catalysts Probed with ${ }^{197}$ Au Mössbauer Effect Spectroscopy, A Goossens, M W J Crajé, A M van der Kraan, A Zwijnenburg, M Makkee, J A Moulijn and $\mathrm{L} \mathrm{J}$ de Jongh, Universities of Delft and Leiden, The Netherlands

Preparation, Characterization and Catalytic Activity of Gold-Based Nanoparticles on HY Zeolites, G Riahi, D Guillemot, M Polisset-Thfoin, A A Khodadadi and J Fraissard, Universities of Paris and Teheran
Professor H-J Freund described how gold as well as silver has been evaporated onto a carefully prepared $\mathrm{TiO}_{2}(110)$ surface of a bulk single crystal as well as on the surface of a well ordered alumina film for comparison. By controlling the evaporation rate as well as the surface temperature metal aggregates of different sizes were grown. Using the conductivity of the substrates it is possible to monitor the morphology and structure of the system with scanning tunnelling microscopy. The results were compared with those obtained previously with a series of transition metals deposited on alumina. Adsorption and desorption of $\mathrm{O}_{2}, \mathrm{CO}$ and $\mathrm{CO}_{2}$ on these systems had been studied by thermal desorption spectroscopy in order to elucidate mechanistic aspects of the low temperature oxidation of carbon monoxide.

An attempt was made to correlate reactivity with the electronic structure of the deposited aggregates. A photon emission scanning tunnelling spectrometer has been developed in which photon emission from individual deposited clusters can be studied by injecting electrons from an STM tip to excite the system. The so-called Mie plasmons of gold and silver deposited on titania and alumina have been studied as a function of the particle size and the behaviour expected for clusters with weak interaction with the substrates observed. In particular, there are no irregularities indicating specific electronic structures for clusters of specific size or shape.

A spectroscopic study of active sites of gold catalysts for the processes of selective and complete oxidation was reported by Nina Bogdanchikova. Using gold supported on alumina as catalyst for the partial oxidation of alcohols and complete oxidation of $\mathrm{CO}$, it was proposed that $\mathrm{Au}^{+}$ions are the active sites in both cases. Additions of $\mathrm{Ce}$ and $\mathrm{Zr}$ oxides increase the selectivity of gold catalysts, whereas addition of La and Cs oxides impair these characteristics in alcohol oxidation. This is caused by stabilization of ionic states of these metals in $\mathrm{Au}-\mathrm{Ce}$ and $\mathrm{Au}-\mathrm{Zr}$ samples and electron-seeking influence of $\mathrm{CeO}_{2}$ and $\mathrm{ZrO}_{2}$ on the active gold sites. In contrast, the electron-releasing effect of $\mathrm{La}, \mathrm{Rb}$ and $\mathrm{Cs}$ oxides lowers the number of active ionic states and their effective charge.

$A$ Goossens reported studies on supported gold catalysts using ${ }^{197} \mathrm{Au}$ Mössbauer effect spectroscopy on $\mathrm{Au} / \mathrm{TiO}_{2}$ and $\mathrm{Au} / \mathrm{TiO}_{2} / \mathrm{SiO}_{2}$ materials used for the selective oxidation of propene to propene oxide. With increasing calcination temperature a gradual formation of metallic gold was observed at the expense of an ionic $\mathrm{Au}{ }^{\mathrm{II}}$-like species. A disturbed, but still metallic surface layer is consistent with the Mössbauer results. 
$J$ Fraissard described an original method for the preparation and study of the catalytic activity of gold and gold-based bimetallic nanoparticles supported on acidic zeolites, $\mathrm{HY}$, ie $\mathrm{Au} / \mathrm{Y}, \mathrm{Pd}-\mathrm{Au} / \mathrm{Y}$ and $\mathrm{Pt} / \mathrm{Au} / \mathrm{Y}$ systems, containing $1-3 \%$ metal. The metal clusters are formed inside the supercages of the zeolite framework by the thermal reduction of cations by the ligands (ethylenediamine). The use of acidic zeolites favours dispersion of the metal and the thermal stability of the particles, achieved via chemical anchoring of the metal clusters to the Brønsted sites of the support. The different mono- and bimetallic catalysts tested on the methylcyclopentane hydroconversion reaction reveal that when gold particles are partially covered by platinum or palladium an increase in the activity and an improvement in the selectivity for isomerization products (cyclohexane and benzene) is achieved to the detriment of hydrogenolysis products. The activity becomes greater than for pure supported platinum or palladium and goes through maxima when the metal content is $c a$ $20 \%$ gold.

\section{Catalytic Gold in Industrial Processes}

Study of Electronic States of Supported Gold in Catalysts for CO Hydrogenation, N Bogdanchikova, J. Navarrete Balañoz, A Pestryakov, M Avalos Borja, J A Diaz and M Farias, Materials Science Centre, Ensenada, Mexico, Mexican Institute of Petroleum, and State University of Tomsk, Russia

In situ FTIR Study of Deactivation of $\mathrm{Au} / \mathrm{TiO} \mathrm{O}_{2}$ Catalysts in Selective Propene Epoxidation, G Mul, A Zwijnenburg, B van der Linden, M Makkee and J A Moulijn, Delft University of Technology, The Netherlands

Low Temperature Water-Gas Shift Reaction on $\mathrm{Au} / \mathrm{CeO}_{2}$ Catalysts, D Andreeva, V Idakiev, T Tabakova, L Ilieva, P Falaras, A Bourlinos and A Travlos, Institute of Catalysis, Sofia, Bulgaria and Institute of Physical Chemistry, Athens, Greece

Direct Gas-Phase Epoxidation of Propene, A Zwijnenburg, A Saleh, M Makkee and J A Moulijn, Delft University of Technology, The Netherlands

Supported Au $+P t$ and Pt/Au Catalysts in Alkane Dehydrogenation-Hydrogenolysis, P A Sermon, F P Getton, D Brown and K M Keryou, Universities of Brunel and Surrey, UK, and University of Botswana
Nina Bogdanchikova described work on the activity and selectivity in hydrogenation of $\mathrm{CO}$ on gold catalysts prepared by the sol gel method, gold being introduced by impregnation, on mixed supports $\mathrm{TiO}_{2}-\mathrm{SiO}_{2}$ containing 5 and $10 \% \mathrm{TiO}_{2}$; the size of the gold particles was $>5 \mathrm{~nm}$. The results were compared with those obtained on reference catalysts $\left(\mathrm{Au} / \mathrm{SiO}_{2}\right.$, $\mathrm{Au} / \mathrm{TiO}_{2}, \quad 5 \% \mathrm{TiO}_{2}-\mathrm{SiO}_{2}$ and $\left.10 \% \mathrm{TiO}_{2}-\mathrm{SiO}_{2}\right)$. Samples were calcined at $450^{\circ} \mathrm{C}$. Gold was found to suppress alcohol formation in the $\mathrm{CO} / \mathrm{H}_{2}$ reaction on the surface of the support and favours $\mathrm{C}_{1}-\mathrm{C}_{4}$ hydrocarbon production : charged states of supported gold were thought to be responsible for this.

In his two presentations, Bart Zwijnenburg described studies on selective propene epoxidation. Highly dispersed $\mathrm{Au} / \mathrm{TiO}_{2}$ catalysts, where the particle size is around $4-6 \mathrm{~nm}$ are very selective in the oxidation of propene to propene oxide, when a combination of $\mathrm{H}_{2}$ and $\mathrm{O}_{2}$ is used as the oxidative mixture but the drawbacks in the epoxidation reaction over $\mathrm{Au} / \mathrm{TiO}_{2}$ catalysts are: (i) the low yield $(1-2 \%)$ obtained under typical reaction conditions (350-450 $\mathrm{K})$, (ii) the low efficiency of hydrogen (relatively large amounts of water are formed), and (iii) significant deactivation of the catalysts within several hours on stream. The conclusions from FTIR studies on $\mathrm{Au} / \mathrm{TiO}_{2} / \mathrm{SiO}_{2}$ and $\mathrm{Au} / \mathrm{TiO}_{2}$ catalysts were that propene is not responsible for deactivation of $\mathrm{Au} / \mathrm{TiO}_{2}$ catalyst: the deactivation is probably due to the formation of the propoxy species on both catalysts. Interestingly, deactivation of a $\mathrm{Au} / \mathrm{TiO}_{2} / \mathrm{SiO}_{2}$ catalyst occurs to a much smaller degree.

$\mathrm{Pt} / \mathrm{Au}$ and $\mathrm{Au}$ only catalysts give comparable propylene oxide yields, but modification of the $\mathrm{Au} / \mathrm{TiO}_{2} / \mathrm{SiO}_{2}$ catalysts with platinum is beneficial for both activity and selectivity: the platinum increases hydrogen and oxygen efficiency and less water is formed, ie the water: propene oxide ratio decreases upon addition of $\mathrm{Pt}$ to an $\mathrm{Au} / \mathrm{TiO}_{2} / \mathrm{SiO}_{2}$ catalyst, whilst the epoxidation activity is maintained. Hydrogenation of propene to unwanted propane does not occur below $372^{\circ} \mathrm{C}$

Donka Andreeva indicated the renewed interest in water-gas shift (WGS), arising from the increased need for pure hydrogen production for use in new fuel-cell power systems. An additional pathway could be the use of the hydrogen produced as a very effective reductant for removing NO. Ceria $\left(\mathrm{CeO}_{2}\right)$ has been shown to be a crucial component of automobile emission-control catalysts, principally because of its role in oxygen storage. In this paper the activities of $\mathrm{Au} / \mathrm{CeO}_{2}$ catalysts for the WGS reaction were reported for the first time. 
A series of three samples of $\mathrm{Au} / \mathrm{CeO}_{2}$ were studied with different gold contents: 1,3 and $5 \mathrm{wt} \%$ Au. The deposition-precipitation method was used to deposit gold hydroxide on suspended ceria in water. The XRD data analysis of the samples indicated that in the $5 \mathrm{wt} \%$ Au sample the average size of gold particles was about 8 $\mathrm{nm}$. The catalytic activity of the samples was evaluated for WGS activity over a wide temperature range (120 $360^{\circ} \mathrm{C}$ ). The addition of gold leads to a considerable increase of the activity and stability of the catalysts.

Paul Sermon described the benefits of gold addition to supported platinum catalysts. The gold modifies propane and butane hydrogenolysis rates and selectivities and enhances dehydrogenation in a way that has potential in the chemical processing of alkanes. Catalysts of this type, where the platinum and gold are separate differ in their reactivity from those where platinum and gold are intimately mixed. The dehydrogenation rate increases as the proportion of gold increases.

\section{Catalytic Gold in Environmental Control}

Oxidation of $\mathrm{CO}$ over $\mathrm{Au} / \mathrm{MO}_{x} / \mathrm{Al}_{2} \mathrm{O}_{3}$ MultiComponent Catalysts in a Hydrogen-Rich Environment, R J H Grisel, C J Westrate and B E Nieuwenhuys, Leiden Institute of Chemistry, The Netherlands

Effect of Treatment on Gold Nanoparticles: Relation Between Morphology, Electron Structure and Catalytic Activity in CO Oxidation, L Guczi, D Horvath, Z Paszti and G Peto, Institutes of Isotope and Surface Chemistry and Technical Physics and Materials Science, Budapest, Hungary

Microstructural Comparison of Calcined and Uncalcined Gold/Ferric Oxide Catalysts for Low Temperature CO Oxidation, N Hodge, C J Kiely, R Whyman, M R H Siddiqui, G J Hutchings, Q A Pankhurst, F E Wagner, R R Rajaram and S E Golunski, Universities of Liverpool and Cardiff, UK, University College, London, UK, Technical University of Munich, Germany, and Johnson Matthey Technology Centre, Reading, UK

Low Temperature Oxidation of $\mathrm{CO}$ over $\mathrm{Au} / \mathrm{MgO}$ and $\mathrm{Au} / \mathrm{Mg}(\mathrm{OH})_{2}$ Catalysts, J L Margitfalvi, A Fási, M Hegedüs and $\mathrm{F}$ Lónyi, Institute of Chemistry, Budapest, Hungary

$\mathrm{N}_{2} \mathrm{O}$ Decomposition on $\mathrm{NiO}$ Supported Gold, C Huggins, C Euesden and P A Sermon, University of Surrey, UK
Gold Catalysts for $\mathrm{CO}$ Sensing in Atmospheres Containing $\mathrm{SO}_{2}, \mathrm{~T}$ Salveson and $\mathrm{P}$ A Sermon, University of Surrey, UK

The Sophia Gold-Based Catalyst, J R Mellor, A Palazov, B S Grigorova, J F Greyling, K Reddy, M P Letsoalo and $\mathrm{J} H$ Marsh, Anglo American Research Laboratories, South Africa

The Beneficial Effect of Gold Additions on the Activity of 'Hopcalite' Catalyst Used for the Low Temperature Oxidation of Carbon Monoxide, S Taylor, R Meyer, I Klingbiel, L Glaner, A Bollmann and E van der Lingen, Mintek, South Africa

What Distinguishes Au-MO from Other LowTemperature Catalysts?, S Golunski, R Rajaram, N Hodge, G J Hutchings and C J Kiely, Johnson Matthey Technology Centre, Reading and Universities of Cardiff and Liverpool, UK

$R J H$ Grisel described results from a project which is motivated by the search for improved automotive catalysts and alternative fuels, designed to meet the ever more stringent legislation associated with automotive exhaust catalysis, and the search for catalysts selective in $\mathrm{CO}$ oxidation in the presence of hydrogen for use in fuel cell systems. The catalysts used in these studies included gold on $\gamma-\mathrm{Al}_{2} \mathrm{O}_{3}$, with additions of several metal oxides, $\mathrm{MO}_{\mathrm{x}}(\mathrm{M}=\mathrm{Mg}, \mathrm{Cr}$, $\mathrm{Mn}, \mathrm{Fe}, \mathrm{Co}, \mathrm{Ni}, \mathrm{Cu}$, and $\mathrm{Zn}$ ). The advantageous effect of $\mathrm{MO}_{\mathrm{x}}$ on the oxidation activity for $\mathrm{CO}$, and to a lesser extent methane, may be twofold: it can stabilize small gold particles and supply oxygen. The catalysts showed an increased activity towards CO oxidation upon water addition only when small gold particles ( $<5 \mathrm{~nm})$ were present.

Generally, the activity of gold-based catalysts in hydrogen oxidation is lower than in $\mathrm{CO}$ oxidation, and this difference was employed in order to design a highly active and selective catalyst for $\mathrm{CO}$ oxidation in the presence of hydrogen. $\mathrm{Au} / \mathrm{MgO} / \mathrm{Al}_{2} \mathrm{O}_{3}$ promotes selective $\mathrm{CO}$ oxidation in hydrogen-rich gases ( $c$ a 70 vol\%) at temperatures for hydrogen fuel cell applications $\left(70-100^{\circ} \mathrm{C}\right)$. The addition of $\mathrm{MgO}$ to the alumina support promotes the formation of small, stable gold particles on the alumina with high surface area and this improves both low-temperature $\mathrm{CO}$ and $\mathrm{H}_{2}$ oxidation by $\mathrm{O}_{2}$. Addition of manganese and iron oxides further enhances low temperature $\mathrm{CO}$ oxidation, with improved $\mathrm{CO}_{2}$ selectivity, by increasing the supply of active oxygen, $\mathrm{eg}$ from lattice oxygen. 
Professor Guczi compared the morphology, electron structure and catalytic activity in $\mathrm{CO}$ oxidation over $\mathrm{Au} / \mathrm{FeO}_{\mathrm{x}} / \mathrm{SiO}_{2} / \mathrm{Si}(100)$ model sample fabricated by pulsed laser deposition with $\mathrm{Au} / \mathrm{Fe}_{2} \mathrm{O}_{3}$ prepared by coprecipitation, and $\mathrm{Au}-\mathrm{Fe} / \mathrm{H}_{\mathrm{a}} \mathrm{Y}(\mathrm{AuHY})$. Gold particle sizes of between 4 and $6 \mathrm{~nm}$ were obtained in all three cases. The mechanism was discussed in terms of the size of gold and the change of the perimeter around the gold/iron oxide interface. The CO molecules are adsorbed on gold and at the perimeter $\mathrm{O}^{2-}$ species are formed and these have a crucial role; this situation does not exist inside the zeolite in the AuHY sample. The proposed mechanism provides an explanation for the connection between the results: furthermore it fits well with relevant literature data.

Christopher Keily described work done in collaboration with Johnson Matthey where gold on iron oxide supports were prepared by inverse coprecipitation from a mixture of $\mathrm{HAuCl}_{4}$ and iron nitrate. Samples dried for $16 \mathrm{~h}$ at $120^{\circ} \mathrm{C}$ exhibited a far superior activity for $\mathrm{CO}$ oxidation than those calcined at $400^{\circ} \mathrm{C}$ for $3 \mathrm{~h}$. The most active material of the former type had been shown to catalyse 100\% $\mathrm{CO}$ conversion at $20^{\circ} \mathrm{C}$ for at least $10 \mathrm{~h}$. The dried samples consist of micron scale agglomerates of 4$8 \mathrm{~nm}$ disordered $\mathrm{Fe}_{5} \mathrm{HO}_{8} .4 \mathrm{H}_{2} \mathrm{O}$ particles on which the gold is uniformly dispersed in the form of a mixture of $\mathrm{AuOOH} \cdot \mathrm{xH}_{2} \mathrm{O}$ and $\mathrm{Au}^{0}$; whereas the calcined materials are comprised solely of $3-5 \mathrm{~nm}$ cuboctahedral metallic $\mathrm{Au}$ particles supported on $20 \mathrm{~nm}$ diameter well-crystalline $\alpha-\mathrm{Fe}_{2} \mathrm{O}_{3}$ particles. The microstructural observations and catalytic measurements were consistent with the mechanism suggested in reference 5 .

József Margitfalvi talked about the low temperature oxidation of $\mathrm{CO}$ over $5 \mathrm{wt} \% \mathrm{Au} / \mathrm{MgO}$ and $\mathrm{Au} / \mathrm{Mg}(\mathrm{OH})_{2}$, prepared by impregnation using $\mathrm{HAuCl}_{4}$. The activity of the $\mathrm{Au} / \mathrm{MgO}$ catalysts strongly depends on the mode of preparation, including (i) the mode of reduction of the gold precursor compound in the slurry, (ii) the temperature of oxygen and hydrogen treatment prior to the reaction, and (iii) the chlorine content. Catalysts calcined without reduction were less active than those calcined and reduced in a hydrogen atmosphere in the temperature range $250-340^{\circ} \mathrm{C}$. An alternative new reaction mechanism was suggested for the $\mathrm{Au} / \mathrm{MgO}$ catalyst.

Paul Sermon first described work on $\mathrm{N}_{2} \mathrm{O}$ decomposition. There is a synergy involving supported gold and its support in the catalysed decomposition of $\mathrm{N}_{2} \mathrm{O}$ that produces one of the lowest reported activation energies for this reaction and this may be of value in vehicle emission control, satellite propulsion, feed purification for air liquefaction and greenhouse gas monitoring.

The second topic was the use of Pt-based catalysts in pellistor-type $\mathrm{CO}$ sensing in air and stack gases from combustion processes. However, there can be problems with $\mathrm{SO}_{2}$ (derived from the fuel) poisoning and deactivating the catalysts. Gold-based catalysts are not so prone to these problems, however. The mechanisms of $\mathrm{SO}_{2}$ interaction with supported $\mathrm{Au}$ surfaces during $\mathrm{CO}$ oxidation were evaluated using real-time residual gas analysis. The potential of $\mathrm{Au}$ catalysts (eg Au/ $\left./ \mathrm{Al}_{2} \mathrm{O}_{3}\right)$ in $\mathrm{CO}$ sensing at moderate temperatures was demonstrated and shown to be less sensitive to deactivation by $\mathrm{SO}_{2}$ than platinum-based sensors.

John Marsh from the Anglo American Research Laboratory described how a gold-based catalyst has been developed and tested as a three-way autocatalyst, as well as for application in the fuel processing subsystems of fuel cells. The catalyst is comprised of gold supported on cobalt oxide along with several additives, which include iron(III) oxide and titanium dioxide. The entire assembly is in turn supported on zirconiastabilized ceria. Apart from the activation of the gold by the transition metal oxides, the most notable feature of the catalyst formulation is a low gold loading of between one and three mass per cent. The three-way catalyst displays a light-off temperature for carbon monoxide of less than $100^{\circ} \mathrm{C}$, while the light-off for hydrocarbons is below $250^{\circ} \mathrm{C}$ and less than $280^{\circ} \mathrm{C}$ for NOx. The catalyst has a working temperature range between $70^{\circ} \mathrm{C}$ and $450^{\circ} \mathrm{C}$.

Rita Meyer indicated that it has been known for many years that a mixture of manganese and copper oxides ('hopcalite') can catalyse the oxidation of $\mathrm{CO}$ to $\mathrm{CO}_{2}$. Commercial hopcalite catalysts contain $\mathrm{CuO}$, $\mathrm{MnO}_{2}$ and, frequently, small quantities of other oxides (acting as activators and promoters) and even $\mathrm{Cu}$ metal. A disadvantage of the standard hopcalite compositions is that they rapidly lose catalytic activity, a problem which is exacerbated by the presence of water vapour. The work described showed that the efficacy of hopcalite can be remarkably enhanced if nano-particles of gold are loaded onto it by either deposition-precipitation or deposition-reduction techniques. The addition of the gold not only improves the activity, but it also prevents the deactivation of the catalyst. The resulting materials were characterized by X-ray diffraction, high resolution scanning electron microscopy and BET surface 
measurement. These techniques revealed that the best activities were achieved with a surprisingly large gold particle size of around $100 \mathrm{~nm}$ on an amorphous substrate with a specific surface area of $130 \mathrm{~m}^{2} \mathrm{~g}^{-1}$. Further optimization of this potentially useful system should be attainable.

Stan Golunski of the Johnson Matthey Technology Centre, UK stated that during the past 15 years, the number of known low-temperature catalysts has been steadily rising. In many instances, the active material is composed of a metallic phase that is well dispersed on or in a metal oxide. Often the low-temperature activity is transitory, but it can also be deliberately induced by specific preparative methods. There are a number of mechanisms for inducing such low-temperature activity: these include normal-support activation (NSA) and active-phase enhancement (APE). The usual roles of the precious metal and the metal oxide support are reversed in NSA, resulting in highly active sites being present on the metal oxide. When gold is well dispersed throughout a defect-forming metal oxide (eg in $\mathrm{CeO}_{2}$ or $\mathrm{ZrO}_{2}$ ) new sites are created for $\mathrm{CO}, \mathrm{NO}$ and alkene conversion (to $\mathrm{CO}_{2}, \mathrm{~N}_{2}$ and $\mathrm{H}_{2} \mathrm{O}$ ). In APE the metal oxide catalyst can be deliberately made to operate at lower temperatures, by providing precious metal sites for oxygen activation, rather than relying on oxide ion transfer through the lattice: with iron(III) oxide, for example, the incorporation of palladium leads to a substantial decrease in the light-off temperature for $\mathrm{CO}$ oxidation, water gas shift and oxidative dehydrogenation. The incorporation of gold does not generally have the same beneficial effect in these types of catalysts, but the presence of gold or palladium can lead to another route to low-temperature activity, which is distinct from NSA and APE: highly reactive peroxide-like intermediates are believed to be formed on exposed gold surfaces and their supply can be sustained when a source of hydroxyl species is available in the immediate vicinity of oxygen-adsorption sites. It was therefore proposed that the peroxide-like intermediates originate at the interface between the gold and an hydroxylated support, and make the gold catalysts particularly effective for carbon monoxide oxidation at low temperatures.

\section{POSTERS}

Bismuthiolate Gold(I) Complexes: The Self-Assembly and Decomposition of Isonitrile Gold Species with Potential for Thin-Layer Gold Deposition and Catalysis, by J D Wilton-Eley, A Schier and H Schmidbaur, Technical University of Munich, Germany
Highly Polar Gold(I) Complexes as Potential Catalysts for the Addition of Nucleophiles to Non-Activated Alkynes, P Roembke, A Schier and H Schmidbaur, Technical University of Munich, Germany

Supported Gold Nanoparticles: In-Depth Catalyst Characterization and Application in Hydrogenation and Oxidation Reactions, C Claus, M Lucas, C Mohr, S Schimpf, U Rodemerck, A Brückner, J Radnik and $\mathrm{H}$ Hofmeister, Institutes of Chemical Technology and Applied Chemistry in Darmstadt and Berlin and Max-Planck Institute, Halle, Germany

Influence of Gold on the Reduction Behaviour of the Au$\mathrm{V}_{2} \mathrm{O}_{5} / \mathrm{TiO}_{2}$ and $\mathrm{Au}-\mathrm{V}_{2} \mathrm{O}_{5} / \mathrm{ZrO}_{2}$ Catalytic Systems: TPR and Kinetic Parameters Evaluation, L Ilieva, G Munteanu, T Tabokova and D Andreeva, Institute of Catalysis, Sofia, Bulgaria and Institute of Physical Chemistry, Bucharest, Romania

Selective Oxidation of Alcohols on Gold Catalysts, A N Pestryakov, V V Lunin and N Bogdanchikova (Tomsk and Moscow State Universities, and Materials Science Centre, Ensenada, Mexico

Kinetic and Adsorption Studies on CO Oxidation with Oxygen over Unsupported Fine Gold Powder, Y Iizuka, Kyoto Institute of Technology, Japan

DRIFTS Studies of the Interaction of Nitric Oxide and Carbon Monoxide in $\mathrm{Au} / \mathrm{TiO}_{2}, \mathrm{M}$ A Debeila, N J Coville, M S Scurrell and G R Hearne, University of Witswatersrand, Johannesburg, South Africa

Anodic Decomposition of Phenols on Electromembranes, M A Maluleke, University of Western Cape, South Africa

James Wilton-Eley described the preparation of the bimetallic species $\left[\left({ }^{\mathrm{t}} \mathrm{BuNCAu}\right)_{2}(\mathrm{SSS})\right]$, the structure of which is a network made up of layers and chains and represents perhaps one of the most complex arrays of molecules based solely on aurophilic contacts: this structure is stabilized through aurophilic interactions in addition to $\mathrm{Au}-\mathrm{N}$ and $\mathrm{Au}-\mathrm{S}$ bonding. This compound has potential for application in the field of polymer-based heterogeneous catalysis.

$P$ Roembke described preparation of the highly polar gold(I) complex $\left[\left(\mathrm{Ph}_{3} \mathrm{P}\right)_{2} \mathrm{Au}\right]^{+}\left[\mathrm{Au}\left(\mathrm{SO}_{2}-p-\mathrm{Tol}\right)_{2}\right]^{-}$. Following the work reported by Teles (see page 59) on 
the use of LAuX complexes as catalysts for the addition of nucleophiles to non-activated alkynes, complexes of this type will now be used to systematically investigate these reactions.

Sabine Schimpf described work on a number of oxidation and hydrogenation reactions using a range of particle sizes $(c a 1-5 \mathrm{~nm})$ of gold on silica, titania and zirconia supports. The intramolecular selectivity for acrolein hydrogenation depends mainly on particle geometry if there is no interaction between gold and the support, but as the particle size decreases the electronic properties of gold become very important (quantum size effects, electron transfer from support Fcentres to the gold surface) and this leads to a drop in selectivity when hydrogenating acrolein to the desired allyl alcohol.

Donka Andreeva described the reduction behaviour of $\mathrm{Au}-\mathrm{V}_{2} \mathrm{O}_{5} / \mathrm{TiO}_{2}$ and $\mathrm{Au}-\mathrm{V}_{2} \mathrm{O}_{5} / \mathrm{ZrO}_{2}$ catalysts. It was established that in the presence of gold the reduction temperature of the $\mathrm{V}^{5+} \rightarrow \mathrm{V}^{3+}$ transition shifted to lower temperatures compared with pure $\mathrm{V}_{2} \mathrm{O}_{5}$ : this leads to higher catalytic activity for the complete oxidation of benzene.

Nina Bogdanchikova described the selective oxidation of methanol on oxide-supported gold catalysts and again proposed that $\mathrm{Au}^{+}$ions are the active sites in the gold catalysts (see page 60). Cerium and zirconium oxides stabilize the ionic states of gold and increase the selectivity of the catalyst.

Yasuo Iizuka has studied carbon monoxide oxidation over unsupported fine gold powder (mean diameter $c a 110 \mathrm{~nm})$ at $273 \mathrm{~K}$ using a closed recirculation system. As received gold powder was inactive but after treatment in oxygen at $423-453$ $\mathrm{K} / 1 \mathrm{~atm}$, gold was an active catalyst and the rate constant was almost independent of temperature. Only $3 \%$ of all the gold surface sites (corner, kink, step and edge sites) absorb $\mathrm{CO}$ reversibly. A large part of the $\mathrm{CO}$ adsorbed on gold powder acts as a spectator during catalytic oxidation, and at most $0.1 \%$ of all the surface gold sites produce $\mathrm{CO}_{2}$ in the $\mathrm{CO}$ pulse reduction.

Mike Scurrell reported his studies on the interaction between $\mathrm{NO}$ and $\mathrm{CO}$ on $5 \mathrm{wt} \% \mathrm{Au} / \mathrm{TiO}_{2}$, prepared by deposition-precipitation, using DRIFTS at $298-373 \mathrm{~K}$. Reduction of the catalyst at $573 \mathrm{~K}$ for 30 min resulted in partial reduction of the gold surface. Adsorption of $\mathrm{NO}$ on $\mathrm{Au} / \mathrm{TiO}_{2}$ is dominated by the formation of dinitrosyl species; whilst adsorption of $\mathrm{CO}$ produces multi-bonded carbonyl which readily reacts with gaseous oxygen to form carbonate. Adsorption of $\mathrm{NO}$ on a CO-covered surface enhances the formation of dinitrosyl species. NO displaced CO from the surface before reaction could occur and no isocyanate species were detected.

$M A$ Maluleke has shown that gold has catalytic activity in the electrochemical degradation of phenols (see also L.D. Burke and P.F. Nugent, Gold Bull., 1998, 31, 39). Gold can also act as a good promoter for a platinum catalyst loaded on a cerium membrane support.

\section{EVENING WORKSHOP}

Professor Graham Hutchings was facilitator for an open discussion evening workshop entitled "Why do gold catalysts work at all?". There was a full attendance of delegates and lively open discussion took place. Gold catalysis has some unusual features, some of which are unique and the mechanisms of the various reactions, particularly carbon monoxide oxidation, which has received more attention than most of the others, was the focus of the considerations. The activity of catalysts depends critically on its method of preparation and the conditions under which it is calcined and used. Various oxidation states of gold may be involved and the interface between the small gold particles and the support seems important. The support plays a key role in supplying oxygen to the gold and thereby increasing its activity. A suggestion was made that a 'standard' gold catalyst should be produced which could be available to workers in the field for comparison purposes. Method of preparation, choice of support(s), gold particle size, and calcination and storage conditions would all need to be carefully defined.

\section{CONCLUSIONS}

This was the first major international conference on gold catalysis and many of the people attending were meeting each other for the first time. The special nature of gold chemistry and gold catalysis came through clearly and there is promise for applications in areas such as pollution control, chemical reactions, fuel cell systems, sensors, and elsewhere: some of these applications may be new, and could be based on the low temperature activity of supported gold or the novelty of the organic transformations catalysed by soluble gold species.

In his concluding remarks, the author highlighted some of the above aspects. He also saw plenty of scope for further development of the very incomplete 
initial research which has taken place to date. In addition to studies aimed at elucidating various aspects of the reaction mechanisms, new work on gold alloy catalysts and new supports should be encouraged. The growing number of patents (see Appendix below) being filed by companies demonstrates industrial interest in exploiting the emerging technologies. There would be a further opportunity for scientists interested in hearing about more new developments in the forthcoming Symposium on Gold and Silver Catalysis taking place in Limerick, Ireland, in September 2001 (see page 49 and inside front cover), as part of the EuropaCatV meeting, 42 papers had already been submitted for this symposium with $c a 85 \%$ of them describing reactions catalysed by gold. The gold papers would cover all the areas discussed at the present conference with the addition of some new topics, including electrocatalysis by gold.

We may be at the beginning of a path where some of the gold presently kept in bank vaults will be called upon to be used in industrial catalytic applications. A second conference in the same series was therefore suggested and the organising committee was charged with identifying a venue and programme for this, probably in North America in 2003. In our post-conference review, it was concluded that more talks of the type presented by Stan Golunski on fuel cell requirements (see page 59) would assist industrialists in assessing where the opportunities for the application of gold catalysts are likely to be most opportune. The local Secretariat, led by Dr M B Cortie (Mintek), were congratulated for the efficiency of their organization of Catalytic Gold 2001.

The proceedings closed with the award by Professor Bond of a Krugerand to the best paper presentation, adjudged to be R J H Grisel from Leiden, The Netherlands. It was pleasing that the whole conference was such a success and this bodes well for the future of catalysis by gold.

\section{REFERENCES}

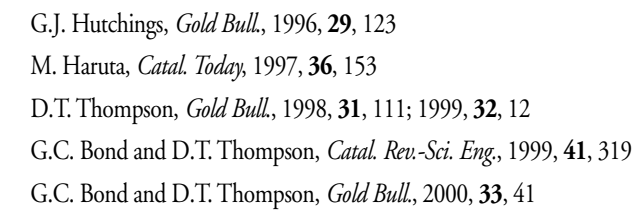

\section{APPENDIX}

Recent patents issued in the field of gold catalysis include the following (see Gold Bulletin, 1998 - 2001):

\section{Related to Processing}

Manufacture of Vinyl Acetate (Pd/Au), T. Wang and J.A. Brossard, Celanese International Corporation, USA, WO Patent 9962632 A1 (1999)

Production of Benzyl Esters (Pd/Au), Y. Sato, J. Tatsumi, T. Iida and T. Hayashi, Nippon Shokubai KK Co Ltd, Japanese Patent 2000288392 A2 (17 October 2000)

Epoxidation of Olefins, S.R. Bare, R.G. Bowman, H.J. Clark, G.E. Hartwell and J.J. Maj, Dow Chemical Company, WO Patent 9800415 A

Carbonylation Catalysts (Ir/Au), J.R. Zoeller, A.H. Singleton, G.C. Tustin and D.L. Carver, Eastman Chemical Company, USA, US Patent 6177380 B1 (23 January 2001)

\section{Related to Pollution Control}

Low Temperature Oxidation of CO, etc, P. Marecot and R. Emmanuel, Rhone Poulenc Chimie, French Patent 27771310 A1 (28 May 1999)

Exhaust Gas Purification and Environmental Control, L.A. Petrov, Laman Consultancy, Bulgaria, WO Patent 9851401 A1 (19 November 1998) (See also Stud. Surf. Sci. Catal., 2000, 130C, 2345-2350)

\section{Related to Fuel Cells}

B. Grigorova, J. Mellor and J.A.J. Tumilty, Anglo American Research Labs, WO Patent 2000013791 (16 March 2000)

V.M. Tatchev, Laman Consultancy, Bulgaria, WO Patent 9916546 A1 (8 April 1999)

\section{Related to Catalyst Preparation}

Gold Compound Solution and its Manufacture, H. Sasaki and M. Kida, Tanaka Noble Metal Industrial Co Ltd, Japan, Japanese Patent 2001048537 A2 (20 February 2001) 